\title{
Comparison of experimental techniques for biocementation of sands considering homogeneous volume distribution of precipitated calcium carbonate
}

\author{
Francisco Centeno Dias ${ }^{1}$, Inês Borges ${ }^{1,2}$, Sofia O. D. Duarte ${ }^{1,3}$, Gabriel A. Monteiro ${ }^{1,3}$ and Rafaela Cardoso (1,* $^{*}$ \\ ${ }^{1}$ IST, Universidade de Lisboa, Av. Rovisco Pais, 1, 1049-001 Lisbon, Portugal \\ 2 INESC-MN, R Alves Redol, 9, 1000-029 Lisboa Portugal \\ ${ }^{3}$ IBB, Av. Rovisco Pais, 1 1049-001 Lisbon, Portugal \\ ${ }^{4}$ CERIS, Av. Rovisco Pais, 1 1049-001 Lisbon, Portugal
}

\begin{abstract}
Microbially induced carbonate precipitation (MICP), or biocementation, consists in using microorganisms living in the soil to produce calcium carbonate (biocement). This mineral bonds the grains and therefore improves the soil hydro-mechanical properties. When using this technique, one of the challenges is to ensure homogeneous treatment in the entire volume. In this study, an experimental device was developed to apply this treatment in cylindrical soil samples with $7.2 \mathrm{~cm}$ diameter and $12 \mathrm{~cm}$ height. Two distinct sample preparation techniques were tested: (i) pre-mixing the soil with bacteria, and then inject the feeding solution; (ii) inject bacteria followed by injecting the feeding solution. In both, the injection conditions varied in two distinct ways: (i) infiltration column, from the top and (ii) injecting through a perforated central tube. The homogeneity of the biocement in the volume was evaluated using X-ray and SEM images from small samples taken from different locations in the specimens and analysing different parameters. Mercury intrusion porosimetry (MIP) and $\mathrm{CaCO}_{3}$ dissolution tests revealed uneven distribution of $\mathrm{CaCO}_{3}$ content between the top and bottom sections, as well as along radial direction. The most homogeneous samples were found when bacteria were premixed with the soil before injecting the feeding solution. Unconfined compression tests (UCS) were also performed in samples with and without treatment. The treatment increased stiffness and strength significantly and soil rupture occurred mostly near the bottom, where the lowest $\mathrm{CaCO}_{3}$ contents were detected.
\end{abstract}

\section{Introduction}

Microbially induced carbonate precipitation (MICP), or biocementation, consists in using microorganisms such as ureolytic bacteria [1] to produce calcium carbonate (biocement). The process involves the hydrolysis of urea $\left(\mathrm{CO}\left(\mathrm{NH}_{2}\right)_{2}\right)$ into carbonate ions $\left(\mathrm{CO}_{3}{ }^{2-}\right)$ and ammonium ions $\left(\mathrm{NH}_{4}{ }^{+}\right)$(Eq. 1) in acid-base reactions where $\mathrm{pH}$ increases. Calcium carbonate, $\mathrm{CaCO}_{3}$, is formed if this process occurs in presence of calcium ions $\left(\mathrm{Ca}^{2+}\right)(\mathrm{Eq} 2)$ [2-3]. These ions and urea are supplied in the feeding solution.

$$
\begin{gathered}
\mathrm{CO}\left(\mathrm{NH}_{2}\right)_{2}+2 \mathrm{H}_{2} \mathrm{O} \rightarrow 2 \mathrm{NH}_{4}^{+}+\mathrm{CO}_{3}^{2-} \\
\mathrm{Ca}^{2+}+\mathrm{CO}_{3}^{2-} \rightarrow \mathrm{CaCO}_{3}
\end{gathered}
$$

Precipitated calcium carbonate bonds the grains and therefore improves the soil hydro-mechanical properties, by: (i) reducing permeability due to the accumulation of precipitate in the soil pores, also known as clogging [4-5]; (ii) increasing strength and stiffness due to bonding generation between soil particles [6-8].
Biocementation technique is a complex process which requires a deep understanding of the factors controlling the bacteria ability to hydrolyze urea. Chemical parameters like the concentration of reagents [9-10] and medium conditions such as alkalinity and temperature $[2,11]$ may be optimized in order to promote high enzyme activity and increase the amount of precipitate. This technique is mostly used in sandy soils because pore sizes must be compatible with bacteria size and allow the transportation of the microorganisms through the soils and their access to the cementation reagents [1,12-14]. An excessive amount of silts and clay soil may hinder this process, and also compromise bacteria adhesion to surfaces, which is another aspect worth of investigation [15].

The distribution of calcium carbonate precipitate is a factor that impacts the range and quality of the treatment [9]. Scale-up experiments such as the one reported by Van Paassen et al [16] achieved an heterogeneously distribution of $\mathrm{CaCO}_{3}$ in the treated volume, and also a significant reduction in cementation with the distance to the injection points. Consequently, and because strength and stiffness increment are connected to the amount of

Corresponding author: rafaela@ civil.ist.utl.pt 
$\mathrm{CaCO}_{3}$ content [3], heterogeneity is also reflected in these mechanical properties [9].

In this work, the effect of several methods for adding bacteria and feeding solution (or cementation solution) were studied aiming to understand their effect on the homogeneity of the distribution of the precipitate. Such knowledge is fundamental to prepare good quality samples for laboratory testing, as well to conceive efficient in situ treatment strategies.

The homogeneity was evaluated using X-ray and SEM images from small fragments extracted from different locations in the specimens. The amount of $\mathrm{CaCO}_{3}$ was quantified by dissolution tests using $\mathrm{HCl}$. Finally, Unconfined Compression (UCS) tests, performed on treated specimens, allowed to compare the gains in strength between methods of injection and also to relate failure modes with the homogeneity of precipitate distribution.

\section{Materials}

\subsection{Soil}

The specimens treated were prepared using a commercial river sand, containing silica minerals according to X-ray tests, and some clay minerals (Kaolinite). Solid particle density was $\mathrm{Gs}=2.64$. The sand classifies as well graded sand (SW) accordingly to the Unified Soil Classification $\left(D_{10}=0.25 \mathrm{~mm}, 4 \%\right.$ of fine particles and $96 \%$ of sand size material).

\subsection{Bacteria and feeding solution}

The bacteria species used was Sporosarcina pasteurii, provided by the American Type Culture Collection (ATCC). Bacteria were grown in a medium containing $20 \mathrm{~g} / \mathrm{l}$ of yeast extract, $10 \mathrm{~g} / \mathrm{l}$ of ammonium sulfate $\left(\left(\mathrm{NH}_{4}\right)_{2} \mathrm{SO}_{4}\right)$ and Tris (concentration $0.13 \mathrm{M}$ ) with $\mathrm{pH}$ adjusted to 9.0 for optimum enzyme activity conditions, at $30^{\circ} \mathrm{C}$ and $250 \mathrm{rpm}$. Growth stage took up to 3 days in order to obtain one void volume of inoculated medium $(200 \mathrm{ml})$, with cell concentration of $\sim 10^{8}$ cells $/ \mathrm{mL}$, corresponding to an optical density of 1 at $600 \mathrm{~nm}$.

The feeding solution was prepared using $0.5 \mathrm{M}$ equimolar solutions of urea and calcium chloride (source of calcium) and 1:10 diluted growth medium. $2.12 \mathrm{~g} / \mathrm{l}$ of sodium bicarbonate and $10 \mathrm{~g} / \mathrm{l}$ of ammonium chloride were added to control the $\mathrm{pH}$ of the medium.

\section{Methods}

\subsection{Sample preparation and experimental setup}

The sand was heated in an oven at $105^{\circ} \mathrm{C}$ for $48 \mathrm{~h}$ to ensure sterilization. Then it was poured dried and vibrated into a cylindrical stainless steel chamber (7.2 $\mathrm{cm}$ diameter and $14 \mathrm{~cm}$ in length) in order to prepare samples with void ratio varying between 0.55 and 0.60 (dry volumetric weights between 16.6 and $17.1 \mathrm{kN} / \mathrm{m}^{3}$ ). Two kinds of samples were prepared: (i) to be treated with bacteria (named B) and (ii) to which only feeding solution was added, for control (named C). In total six specimens were prepared.

As presented in Figure 1, a drain composed by a geotextile filter and a layer made of gravel (1 cm thick) was added to the top and bottom sections of the specimens, therefore the final height of the soil samples was $12 \mathrm{~cm}$. The chamber had top and bottom valves to allow the inlet and outlet of bacteria and feeding solutions, and therefore allowing fluid circulation during the treatment.

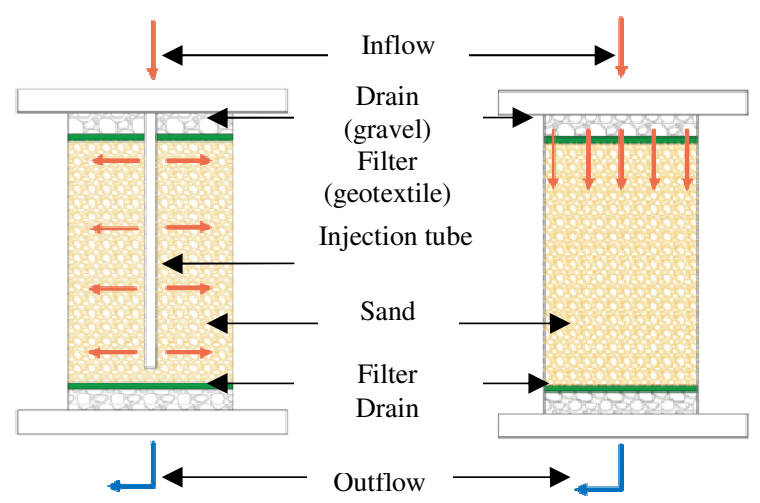

Fig. 1. Scheme of the inoculation chamber and injection methods tested (left: injection using a perforated central pipe; right: percolation as an infiltration column).

Three different loads of bacteria were tested using the solution with bacteria and culture medium (Table 1): (i) injection through a perforated central tube (Fig. 1 left), (ii) injection at the top to promote percolation as an infiltration column (Fig. 1 right), or (iii) pre-mixing them with the soil before been placed in the chamber.

Table 1. Addition of bacteria and injection methods tested.

\begin{tabular}{|c|c|c|}
\hline Name & Addition of bacteria & Feeding method \\
\hline B2st & Infiltration column & Infiltration column \\
\hline B2ct & Injection tube & Injection tube \\
\hline B3st & Pre-mixed & Infiltration column \\
\hline B3ct & Pre-mixed & Injection tube \\
\hline C1 (control) & $\begin{array}{c}\text { Culture medium with } \\
\text { no bacteria }\end{array}$ & Infiltration column \\
\hline C2 (control) & $\begin{array}{c}\text { Culture medium with } \\
\text { no bacteria }\end{array}$ & Injection tube \\
\hline
\end{tabular}

Feeding was done through injection: (i) using the central perforated tube $(5 \mathrm{~mm}$ and $3 \mathrm{~mm}$ outside and inside diameters, respectively), or (ii) infiltration from the top as an infiltration column. As summarized in Table 1, the same method used to inject bacteria was also used to inject the feeding solution: if the tube was used for injecting bacteria it was also used to inject the feeding solution, while when the infiltration column was used to add bacteria, also feeding was done using this method. The two feeding injection methods were tested when bacteria were pre-mixed with the soil, as well as for the control specimens. 
When the bacteria solution was injected to the soil specimen, a $20 \mathrm{ml}$ syringe was connected to the top of the chamber. The infiltration tube, when used, was connected to this valve. Without the tube, the valve would connect to the upper drainage layer and the system worked as an infiltration column. Concerning the addition of the feeding solution, the injection of this fluid was done in the tube or in the upper drain using a pressure/volume controller working as a pumping station. The experimental setup is shown in Fig 2.

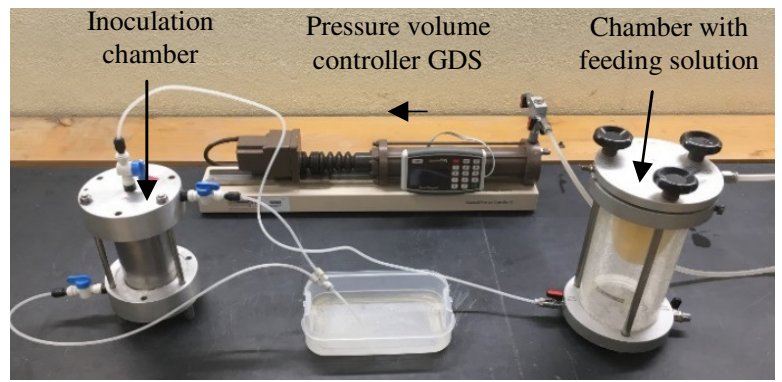

Fig. 2. Experimental setup.

Two hundred $\mathrm{cm}^{3}$ of culture medium containing bacteria (equal to the specimen pore volume) was added to the soil at the beginning of the treatment, whether by pre-mixing it or by addition to the sample in the chamber. In total four additions of feeding solution were performed at $24 \mathrm{~h}$ intervals. At the end of each feeding, the inoculation chamber rested $2 \mathrm{~h}$ at $35 \pm 3^{\circ} \mathrm{C}$ for improving enzyme activity [5,12]. The flow rate was kept constant at $360 \mathrm{ml} / \mathrm{h}$ (or 1.7 pore volume/h) aiming to keep low and constant the pressure inside the chamber to avoid leakage.

\subsection{Distribution of $\mathrm{CaCO}_{3}$}

\subsubsection{Type and presence of $\mathrm{CaCO}_{3}$ minerals}

The homogeneity of the treatment was evaluated through the volumetric distribution of $\mathrm{CaCO}_{3}$ precipitate in each treated specimen. Small samples were extracted along radial and longitudinal direction, near the top, in the middle and near the bottom.

The presence and different mineral forms of $\mathrm{CaCO}_{3}$ (calcite, vaterite or aragonite) was investigated through scanning electron microscope (SEM) images and X-ray diffraction tests (XRD). The presence of calcium element was detected at SEM using electron diffraction (EDS).

Precipitate presence was detected adopting an alternative way by using mercury intrusion porosimetry tests (MIP). In fact, it is expected the reduction of pore dimensions due to clogging with precipitate. Cubic samples $\left(1 \times 1 \times 1 \mathrm{~cm}^{3}\right)$ were carved from the top, middle and bottom zones of the specimen. Only samples extracted from the radial and near the cell wall (lateral) positions were investigated for the samples where bacteria were added. There is no data on the control specimens because their non-cohesive nature prevents sample extraction.

\subsubsection{Quantification of precipitate minerals}

$\mathrm{CaCO}_{3}$ content was measured by acid dissolution using $\mathrm{HCl}(0.5 \mathrm{M})$. In this test, the weight of the dried samples was recorded and acid was added while $\mathrm{CO}_{2}$ bubbles liberated in the reaction was occurring. The mixture was then washed using distilled water, filtered with filter paper, the residue was oven dried at $105^{\circ} \mathrm{C}$ for $24 \mathrm{~h}$ and the final weight was measured. The difference between the initial and final weights is the weight of the carbonate present in the original sample. The $\mathrm{CaCO}_{3}$ content is the ratio between mass loss and the final weight.

\subsection{Mechanical properties}

Unconfined compression tests, UCS, were performed to analyse the improvements on the mechanical properties of the material due to the treatment. The specimens were covered with a loose latex membrane to minimize material loss during the test and avoid introducing confinement, which could affect the results. Axial loading velocity was $0.5 \mathrm{~mm} / \mathrm{min}$.

Strength $\left(\mathrm{q}_{\mathrm{u}}\right)$ was assumed to be the peak value measured. Stiffness $\left(\mathrm{E}_{50}\right)$ was determined as the tangent to the axial load-axial deformation curve for $50 \%$ of the peak value.

\section{Results and discussion}

\subsection{Distribution of $\mathrm{CaCO}_{3}$}

\subsubsection{Type and presence of $\mathrm{CaCO}_{3}$ minerals}

The results from XRD tests are presented in Table 2. The presence of calcium carbonate in the form of calcite mineral was detected in all specimens. The highest scores found for this mineral were obtained with the samples extracted from the top sections. This can be explained by the fact that these are the zones closest to the inlet.

Table 2. Minerals identified by the XRD analysis

\begin{tabular}{|c|c|c|}
\hline Specimen & Properties & Name of the minerals (score) \\
\hline $\begin{array}{c}\text { Untreated } \\
\text { sand }\end{array}$ & --- & $\begin{array}{c}\text { Quartz (53), Microcline (18), } \\
\text { Muscovite (26), Kaolinite (14) }\end{array}$ \\
\hline B2ct & $\begin{array}{c}\text { Top } \\
\text { section }\end{array}$ & $\begin{array}{c}\text { Untreated sand minerals, } \\
\text { Calcite (27) }\end{array}$ \\
\hline B2ct & $\begin{array}{c}\text { Bottom } \\
\text { section }\end{array}$ & $\begin{array}{c}\text { Untreated sand minerals, } \\
\text { Calcite (27) }\end{array}$ \\
\hline B2st & $\begin{array}{c}\text { Top } \\
\text { section }\end{array}$ & $\begin{array}{c}\text { Untreated sand minerals, } \\
\text { Calcite (32) }\end{array}$ \\
\hline B2st & $\begin{array}{c}\text { Bottom } \\
\text { section }\end{array}$ & $\begin{array}{c}\text { Untreated sand minerals Calcite } \\
(10)\end{array}$ \\
\hline
\end{tabular}

From SEM images it was possible to find different forms of $\mathrm{CaCO}_{3}$ crystals (calcium presence confirmed by EDS, not presented here):

- Cubic form with reduced size (5 to $20 \mu \mathrm{m}$ ) (Fig 3). 
- Crystalline structure, like a rosette, present on all samples and with dimension varying between 20 and $40 \mu \mathrm{m}$ (Fig 4).

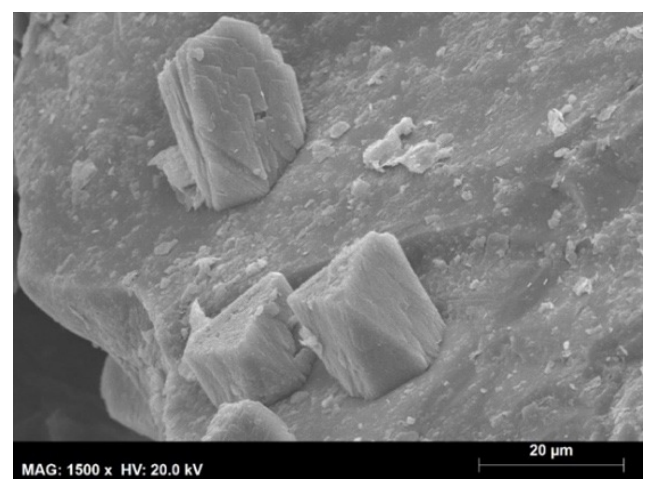

Fig. 3. SEM images of sample B2ct showing cubic crystals of $\mathrm{CaCO}_{3}$, typical of calcite.

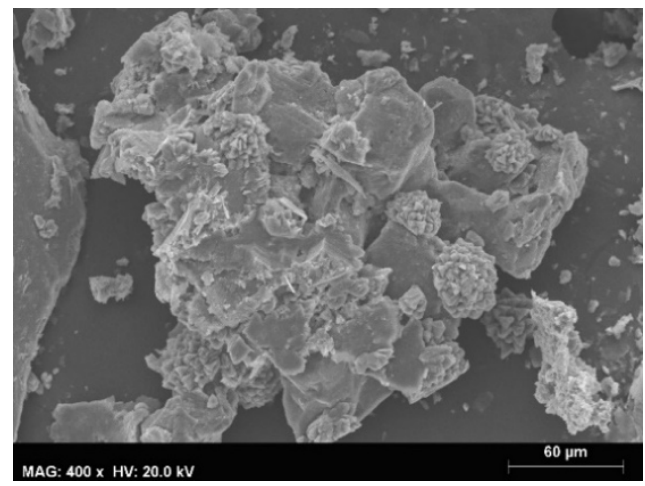

Fig. 4. Sand particles bonded by $\mathrm{CaCO}_{3}$ crystals (rosette like shape).

The formation of sand aggregates bonded by $\mathrm{CaCO}_{3}$ crystals can be observed in Fig. 4 (sample B3st). These bonds explain the mechanical improvements observed. They also provide some pore clogging, which is intended to be detected in MIP tests. These tests were performed only in the injected specimens B2ct and B2st because large heterogeneity is expected when using injection.

Figure 5 presents the results found in MIP tests for specimen B2ct in samples extracted from the middle section, one near the tube (center) and the other far from it, next to the chamber wall (lateral). It can be seen monomodal pore size distributions in which the dominant pore size (corresponding to the highest peak) displaced left in the center sample when compared with the lateral sample. This result indicates that pore clogging was higher at the centre, near the injection tube.

For the other specimen where no tube was used, B2st, the samples at the bottom were broken and therefore no MIP data is available. However in the middle section of this specimen a good homogeneity along the radial direction was found. This is shown in Fig. 6, which presents the values of the pore sizes to which a peak was detected in MIP tests for specimens $\mathrm{B} 2$ st and B2ct in the different zones and radial locations. Independently from the procedure used to add bacteria, the smallest pore sizes were detected in the top sections, indicating that clogging could be larger there then in the bottom. When comparing the two procedures, when the tube was used it appears that the lateral values are quite similar independently from the zone in the sample.

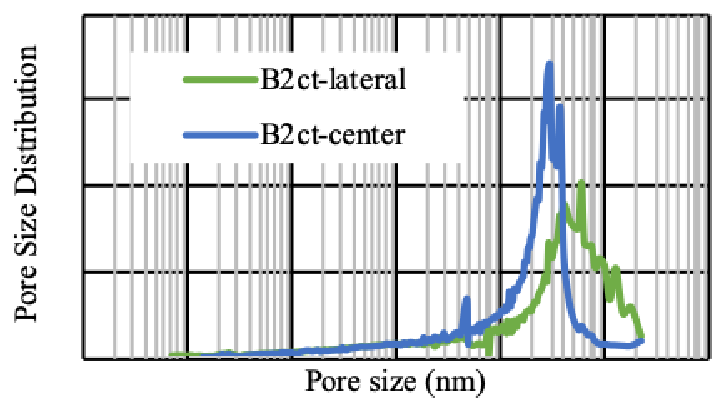

Fig. 5. Comparison of pore size distribution curves between radial positions of the top section of specimen B2ct.

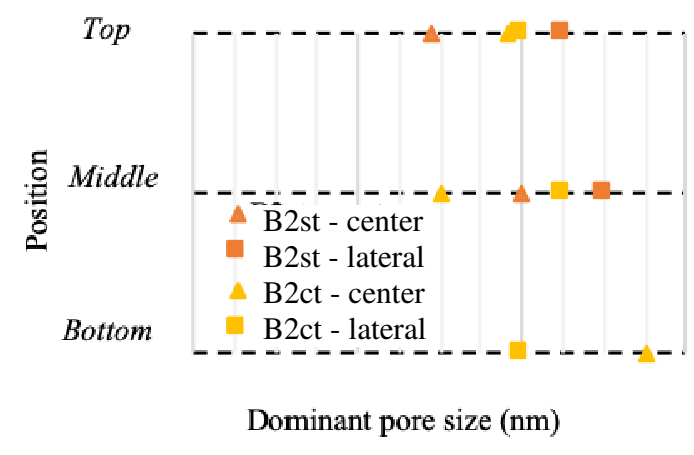

Fig.6. Distribution of dominant pore size detected in MIP tests for samples extracted in different zones of the specimens.

Finally, a significant dispersion was found for the two treatment methods for the three zones, although MIP tests results appear to indicate that the precipitate will concentrate more in the top of the samples.

\subsection{2 $\mathrm{CaCO}_{3}$ content}

The results from the $\mathrm{HCl}$ dissolution tests performed to quantify the amount of calcium carbonate precipitate are presented in Fig. 7 for the injected specimens B2st and B2ct, and in Fig. 8 for the specimens B3st and B3ct, where bacteria were premixed with the soil.

For the cases B2ct and B2st (Fig. 8), the $\mathrm{CaCO}_{3}$ contents varied between $1.8 \%$ and $4.2 \%$. Overall, better results were found when the tube was used. Indeed, for specimen B2ct the difference in content between lateral and center positions was almost null along the specimen, and the maximum difference found between top and bottom sections was inferior to $0.9 \%$ (Fig 8). In both specimens it is visible a decrease in the amount of precipitate at the bottom, far from the inlet zone. This can be explained by the longer distance bacteria and feeding solution must travel to arrive at the bottom sections. This results is also in accordance with MIP results (Fig. 6) and justified doing such tests only for 
these samples.

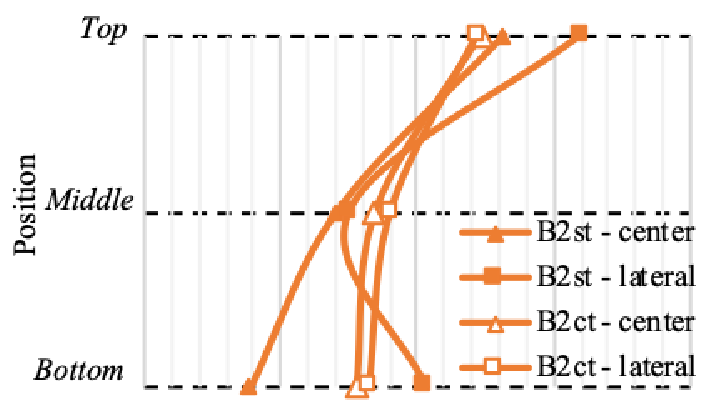

$\mathrm{CaCO} 3$ content $(\%)$

Fig. 8. $\mathrm{CaCO}_{3}$ content distribution in the specimens to which bacteria was injected to the soil.

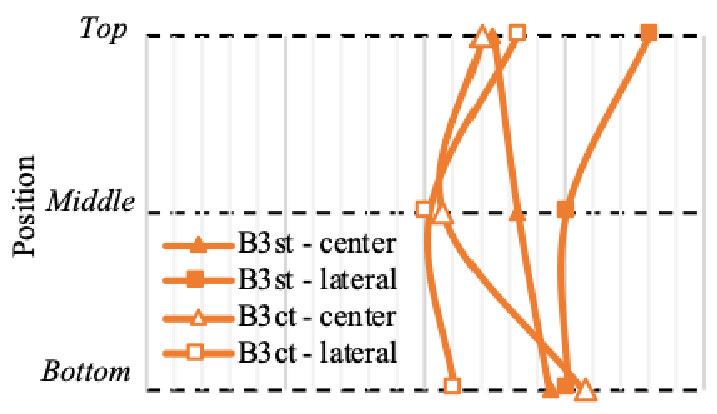

CaCO3 content $(\%)$

Fig. 9. $\mathrm{CaCO}_{3}$ content distribution in the pre-mixed specimens.

Calcium contents increased to values between $3.0 \%$ and $4.6 \%$ when bacteria were premixed with the soil, for specimens B3st and B3ct (Fig. 9). This indicates that premixing can favor biocementation. The injection tube seemed to not to have large impact on the homogeneity for these samples. Indeed, along radial distribution the difference was $1.0 \%$ (Fig 9) and the difference between top and bottom sections was around $1.0 \%$. This difference is less marked than the one observed when bacteria were injected to the soil, which confirm that premixing leads to better homogeneity than injecting bacteria. This is because mixture is more efficient if done before placing the soil in the chamber.

Finally, control specimens $\mathrm{C} 1$ and $\mathrm{C} 2$, treated only with feeding solution, revealed $\mathrm{CaCO}_{3}$ content between $1.3 \%$ and $1.4 \%$. Although no bacteria was used to catalyze biocementation reactions, some calcium carbonate precipitate was found, probably from the natural reactions by indigenous bacteria and nondissolved carbonates with no cementation function in the soil.

\subsection{Unconfined compression tests}

Table 3 summarizes the main results of the unconfined compression tests performed: unconfined compression strength $\mathrm{q}_{\mathrm{u}}$ and the corresponding axial deformation $\delta \varepsilon_{\text {peak }}$, as well as stiffness $\mathrm{E}_{50}$.
The comparison between the values measured for the treated and untreated (control) specimens show clearly strength increment up to nine times: $18 \mathrm{kPa}$ for the control specimens ( $\mathrm{C} 1$ and $\mathrm{C} 2$ ), while values between 60 and $150 \mathrm{kPa}$ were measured on the treated specimens. The highest value was measured at specimen B3st, premixed with bacteria. For the specimens were bacteria were added, better results were found for injection using the tube than using infiltration (120 and $100 \mathrm{kPa}$, respectively). Contrary to expectations, the lowest strength value $(60 \mathrm{kPa})$ was measured for specimen $\mathrm{B} 3 \mathrm{ct}$ pre-mixed with bacteria. This can be explained by instability due to the tube presence inside the specimen, which exhibited column buckling type behavior. Specimen B2ct also had a tube inside, but the tube was partially removed before the test and therefore its interference was minimized.

Table 3. Summary of the results from UCS tests.

\begin{tabular}{|c|c|c|c|c|}
\hline & Specimen & $\mathbf{q}_{\mathbf{u}}(\mathbf{k P a})$ & $\boldsymbol{\delta}_{\text {peak }}(\boldsymbol{\%})$ & $\mathbf{E}_{\mathbf{5 0}}(\mathbf{M P a})$ \\
\hline \multirow{2}{*}{ Control } & $\mathrm{C} 1$ & 18 & 4.5 & 0.35 \\
\cline { 2 - 5 } & $\mathrm{C} 2$ & 18 & 5.7 & 0.36 \\
\hline \multirow{2}{*}{$\begin{array}{c}\text { Bacteria } \\
\text { added }\end{array}$} & $\mathrm{B} 2 \mathrm{st}$ & 99 & 2.9 & 4.96 \\
\cline { 2 - 5 } & $\mathrm{B} 2 \mathrm{ct}$ & 120 & 3.7 & 4.79 \\
\hline \multirow{2}{*}{$\begin{array}{c}\text { Pre-mixed } \\
\text { bacteria }\end{array}$} & $\mathrm{B} 3 \mathrm{st}$ & 150 & 2.9 & 6.89 \\
\cline { 2 - 5 } & $\mathrm{B} 3 \mathrm{ct}$ & 60 & 2.8 & 3.48 \\
\hline
\end{tabular}

Stiffness $\mathrm{E}_{50}$ increased after treatment from $0.35 \mathrm{MPa}$ (C1 and $\mathrm{C} 2$ ) to a maximum of $6.9 \mathrm{MPa}$ found in the premixed specimen B3st. The lowest stiffness measured of 3.5 MPa was found for specimen B3ct, which can be explained by the interference of the inner tube. Concerning the bacteria injected specimens, both B2ct and B2st had similar stiffness, around 5.0 MPa (Table 3).

The two specimens to which bacteria were added (B2st and B2ct) presented small vertical cracks and crushing at the bottom section (Fig 10, left). The specimens pre-mixed with bacteria (B3st and B3ct) exhibited a marked shear failure surface, characteristic of fragile behavior (Fig 10, right), but the one without tube, B3st, showed also signs of crushing near the bottom section. Both the control specimens showed volumetric deformation at the middle section with no visible failure surfaces. It is worth to note that it was impossible to remove the inner pipe to without destroying the samples, and also that the geotextile was not interfering with the failure surface observed.

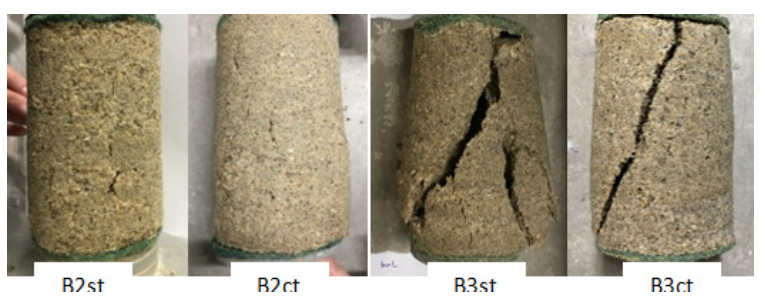

Fig. 10. Failure of the different specimens. 
The failure modes presented in Fig. 10 show a transition from crushing failures in the bottom sections to a more fragile failure in which shear surfaces are formed. The first was observed in the specimens to which bacteria were added, while the last was found for the specimens pre-mixed with bacteria:

Crushing failure near the bottom in the specimens to which bacteria was injected may be explained by the lack of cementation in this section compared to the others. This was observed in the dissolution tests (Fig 8) and in the MIP tests (Fig 6), where lowest $\mathrm{CaCO}_{3}$ concentration and larger pore sizes were found at the bottom.

The transition into a shear failure observed in the specimen where bacteria were pre-mixed is justified by the homogenization of the $\mathrm{CaCO}_{3}$ content in the entire volume, and also by an increase of overall cementation. In fact, a larger amount of $\mathrm{CaCO}_{3}$ content was found for the pre-mixed specimens when compared with the specimens to which bacteria were added (Figs. 8 and 9).

\subsection{Joint analysis of all data}

Pre-mixing the bacteria appeared to improve homogeneity and overall cementation of the soil. This is because the percentages of $\mathrm{CaCO}_{3}$ found along the $\mathrm{B} 3 \mathrm{ct}$ and B3st specimens were all above 3\% (Fig. 9), all larger than the percentages found for the $\mathrm{B} 2 \mathrm{Ct}$ and $\mathrm{B} 2 \mathrm{st}$ specimens. This may be explained by a smoother distribution of the bacteria in the soil and thus a better volume distribution of potential sites for formation of calcium carbonate. This homogeneity appears to be independent from the method adopted to inject the feeding solution. The overall cementation state was $4.1 \%$ for B3st and 3.4\% for B3ct, and also a high compression strength and stiffness was measured in the specimens where no injection tube was added (Table 3). Possibly the marked improvement on the mechanical properties would also be observed in the presence of the inner tube if it would be removed before the tests.

When bacteria was injected to the soil, (Fig. 8), better homogeneity along axial and radial directions was found in the injected specimen B2ct when compared with B2st because the difference between top and bottom sections was only $0.9 \%$ in the first case and $2.4 \%$ of in the second. This corresponds to stiffness and strength better in specimen B2ct than in B2st. Therefore, the perforated tube allowed a better homogeneous distribution and, consequently, better mechanical improvement than when inject the treatment as infiltration column.

\section{Conclusions}

Pre-mixed specimens showed the best homogeneity and highest overall cementation indicators. The tube hindered the renovation of the feeding solution inside the chamber. Nevertheless, the amount of precipitate formed was smaller than when feeding was done as infiltration column.

The inclusion of a perforated tube in the interior had a large impact on the specimens where bacteria were injected because it helped homogenizing bacteria distribution, and latter the feeding solution. When bacteria injection and feeding were done as infiltration column the amount of precipitate decreased, in particular in the bottom sections far from the inlet.

Finally, strength increments were observed in the all treated specimens, showing that treatment worked independently from the procedure adopted.

\section{Acknowledgements}

The authors acknowledges funding from the Portuguese Foundation for Science and Technology, FCT I.P., project BIOSOIL, ref. PTDC/ECI-EGC/32590/2017.

\section{References}

1. J.K. Mitchell, J.C. Santamarina. Journal of Geotech and Geoenv. Engng, 131, 1222-1233 (2005)

2. S. Stocks-Fischer, J.K. Galinat, S.S. Bang, Soil Biology and Biochemistry, 31, 1563-1771 (1999).

3. H. Yasuhara, D. Neupane, K. Hayashi, M. Okamura, Soils and Foundations, 52, 539-549 (2012)

4. U.K. Gollapudi, C.L. Knutson, S.S. Bang, Journal of Geotech. Geoenv. Eng. ASCE, 120, 259. (1995)

5. M. Nemati, E.A. Greene, G. Voordouw, Process Biochemistry, 40, 925-933 (2005)

6. L.A. Van Paassen, M.P. Harkes, G.A. Van Zwieten, W.H. Van der Zon, W.R.L. Van der Star, M.C-M Van Loosdrecht, Proc. 17th Int. Conf. Soil Mech. Geot. Engng: The Academia and Practice of Geotechnical Engineering, 3, 2328-2333 (2009)

7. J.M. Whitaker, S. Vanapalli, D. Fortin, Biogeosciences, 15, 4367-4380 (2018)

8. J.T. DeJong, M.B. Fritzges, K. Nüsslein, J. Geotech. Geoenv. Eng., 132, 1381-1392 (2006)

9. V.S. Whiffin, L.A. Van Paassen, M.P. Harkes, Geomicrobiology Journal, 24, 417-423 (2007)

10. A. Al Qabany, K. Soga, J.C Santamarina, J. Geotech. Geoenv. Eng., 138, 992-1001 (2012)

11. K.L. Sahrawat, P.O. Patancheru, Plant and Soil, 8, 401-408 (1984)

12. N. Wei-Soon, L.M. Lee, H. Siew-Ling, World Academy of Science, Engineering and Technology, 62, 723-729 (2012)

13. F. Hammes, W. Verstraete, Reviews in Environmental Science and Bio-Technology, 1, 3-7. (2002)

14. R. Cardoso, I. Pires, S.O. Duarte, G. Monteiro, Applied Clay Science, 156, pp. 96-103 (2018)

15. M.P. Harkes, L.A. Van Paassen, J.L. Booster, V.S. Whiffin, M.C.M. Van Loosdrecht, Ecological Engineering, 36, 112-117 (2010)

16. L.A. Van Paassen, R. Ghose, T.J.M. Linden, W.R.L. Van der, Star, M.C.M. Van Loosdrecht, J. Geotech. Geoenv. Eng., 136, 1721-1728 (2010) 